\title{
CABO TOCO: UMA ENFERMEIRA QUE SE TORNOU COMBATENTE
}

CABO TOCO: A NURSE WHO BECAME A FIGHTER

\author{
Renata Colbeich da Silva \\ renatacolbeich@hotmail.com \\ Universidade Federal de Santa Maria (UFSM) \\ Mestra em Ciências Sociais - UFSM \\ ORCID: http://orcid.org/0000-0002-2293-5451
}

\section{Ceres Karam Brum}

cereskb@terra.com.br

Universidade Federal de Santa Maria (UFSM)

Doutora em Antropologia Social (PPGAS-UFRGS)

ORCID: https://orcid.org/0000-0001-6152-8616

\section{Suzana Cavalheiro de Jesus}

suzanacavalheirodejesus@gmail.com

Universidade Federal do Pampa (Unipampa)

Doutora em Antropologia Social (UFSC)

ORCID: $h t t p: / / o r c i d . o r g / 0000-0002-5218-9816$

\section{(c) (1)(2)}

Esta obra está licenciada sob uma licença Creative Commons Attribution-NonCommercial-ShareAlike 4.0 International License.

\section{RESUMO}

Olmira Leal de Oliveira, popularmente conhecida no Rio Grande do Sul como Cabo Toco, foi a primeira mulher gaúcha a servir à Brigada Militar no estado. Ao longo de sua trajetória lutou pelo reconhecimento de seus feitos nos confrontos armados de 1923, 1924 e 1926, período conhecido na história gaúcha pelas disputas entre Maragatos e Chimangos. Com base numa pesquisa etnográfica a respeito de narrativas (auto) bibliográficas sobre Cabo Toco, o presente texto leva em consideração as representações, experiências, representatividade e memória percebidas por mulheres que têm em Olmira um ideal a ser seguido.

Palavras-chave: Cabo Toco; narrativas; experiências.

\section{ABSTRACT}

Olmira Leal de Oliveira, popularly known in Rio Grande do Sul as Cabo Toco was the first Gaucho woman to serve the Military Brigade in the state. Throughout her trajectory, she has fought for the recognition of her accomplishments in the armed conflicts of 1923, 1924, and 1926, 
which marked the historical period of Maragatos versus Chimangos. Based on ethnographic research on (self) bibliographic narratives about Cabo Toco, the present text considers the social representations around these narratives produced, given their symbolism, experiences, representativeness, and memory in the life of other women who have in Olmira, an ideal to follow.

Keywords: Cabo Toco; narratives; experiences.

\section{INTRODUÇÃO}

O objetivo desta etnografia é apresentar um conjunto de reflexões a respeito da figura de Cabo Toco, realizadas a partir do ano de 2015. Tratam-se de representações acerca da vida de Olmira Leal de Oliveira, a Cabo Toco, percebidas através de narrativas autobiográficas de mulheres. Neste sentido, tentou-se compreender a forma como eram produzidas as narrativas sobre Cabo Toco e como estas memórias circulavam na cidade de Cachoeira do Sul, cidade localizada, geograficamente, na região central do Rio Grande do Sul.

A construção etnográfica partiu da percepção das experiências de um conjunto de mulheres na cidade de Cachoeira do Sul que, ao mesmo tempo que contavam sobre sua vida cotidiana, em forma de autobiografia, narravam sobre a vida de Cabo Toco. Chamou atenção o fato de guardarem consigo diferentes recortes de jornais e revistas, fazendo referência a informações salvaguardadas no museu municipal de Cachoeira do Sul e, ainda, a outras mulheres narradoras. Tal recurso permitiu que uma narradora indicasse a outra pelo discurso do "eu não sei contar, mas a fulana sabe..." (HARTMANN, 2011, p. 8).

Com relação às fontes documentais, optou-se pela utilização da etnografia em arquivos, de Elsie Rockwell (2011), a partir da tentativa de compreender o escritor e seus escritos pelos balizamentos do tempo vivido, tendo em vista a dimensão da prática viva das palavras, compreendendo sua presença em qualquer lugar, atentando às entrelinhas e ao não escrito (ROCKWELL, 2011).

A etnografia foi inspirada por uma busca de descrição densa (GEERTZ, 1989), em que foi possível identificar arquivos, compostos por documentos ${ }^{1}$ jornalísticos sobre Cabo Toco, bem como narrativas orais, formuladas por uma rede de narradoras mulheres unidas por profissões em comum, professoras ou enfermeiras, ligadas à referente por diferentes vivências. A descrição densa, utilizando diferentes fontes etnográficas, possibilitou "construções de construções" interpretativas por meio de teias de significados, que passaram a orientar a experiência humana através de um sistema de símbolos, no qual cada indivíduo envolvido estabeleceu uma interação recíproca com a representação de Cabo Toco (GEERTZ, 1989). 
Pelos documentos constatou-se a lembrança de Cabo Toco no esquecimento, pela velhice e condições precárias em que se encontrava naquele momento da vida. Pelas falas das narradoras, notou-se a construção de uma agência diante de uma experiência de vida a ser seguida, remetida ao empoderamento feminino, reciprocidades e aprendizados sobre a vida, nas quais retratam não só Cabo Toco, mas também autobiografias orais e memórias de quem narra. Diante disto, o presente artigo apresenta reflexões e contextos em que afloraram narrativas sobre Dona Olmira Leal de Oliveira enquanto heroína para um grupo de mulheres enfermeiras e professoras da cidade de Cachoeira do Sul-RS. Estas, ao compartilharem diferentes experiências narrativas, narram sobre si numa trajetória autobiográfica, mas ao mesmo tempo narram sobre Cabo Toco.

Num primeiro momento, "o que contam sobre Olmira" é construído por bricolagem (LÉVI-STRAUSS, 1976) de diferentes falas sincrônicas e diacrônicas, logo após a apresentação e sobre diversas considerações acerca da mulher no Rio Grande do Sul e seus reflexos na representação documental sobre Cabo Toco. Por fim, a narrativa de quem fala sobre si ao narrar sobre Olmira Leal de Oliveira em diferentes formas de construções de memória e identidade.

As narrativas que aqui serão apresentadas, em seus sentidos e carga simbólica, proporcionaram projeções e práticas sociais na tentativa de compreender padrões que se tencionam no imaginário social vigente, dados pelos acontecimentos do passado projetado nos agentes do futuro. A análise tanto das narrativas orais, quanto jornalísticas, sobre Cabo Toco, tornaram-se indispensáveis para compreender como expressões simbólicas organizam e transmitem experiências, sejam elas reais, ouvidas ou imaginadas (HARTMANN, 2011). A história não é simplesmente algo que acontece às pessoas, mas algo que elas fazem (ORTNER 2007), seja na realidade ou em seu imaginário, produzindo e reproduzindo costumes no cotidiano, valendo-se da necessidade de pensar nas falas populares que caracterizam lugares e transpõem tradições. E são chaves importantes na organização e transmissão da experiência de viver (HARTMANN, 2011).

Nomes fictícios foram atribuídos às narradoras, garantindo seu anonimato e segurança na livre expressão das palavras. Os nomes partiram da referência a outras mulheres que, de algum modo, contribuíram para a história das mulheres no/do Brasil e que estão citadas em um dos arquivos que compuseram a pesquisa, a saber, a Revista Tempo 16 (s.d.). São mulheres que constroem e levam simbolismo da luta feminina por prestígio, assim como Olmira Leal de Oliveira. Elas são: Anita Garibaldi e sua ousadia de contestar, pela reversão de um papel de submissão feminino, fugindo com Giuseppe Garibaldi² e lutando ao seu lado na revolução Farroupilha; Joana Galvão, a heroína da batalha na primeira tomada 
da Colônia do Sacramento pelos caminhos espanhóis em 7 de agosto de 1680; Chica Papagaia, a Maria Francisca Ferreira Duarte, amante de David Canabarro 3 , que protagonizou o episódio de guerra da "Traição de Porongos", recaindo sobre si a culpa pelo ataque ao acampamento farroupilha e morte de Canabarro; Frutuosa da Silva, neta de Chica da Silva, que, ao lutar pela recuperação do patrimônio de seu avô, João Fernandes de Oliveira, teria auxiliado a escrever a biografia de sua avó; e ainda Zeferina Dias, líder feminina do quilombo do Urubu, que com seu arco e flecha defendia seu território dos homens brancos na Bahia.

\section{ENTRE SINCRONIAS E DIACRONIAS: O QUE CONTAM SOBRE CABO TOCO?}

A história de Cabo Toco é uma história que pertence à guerra. Segundo seus documentos pessoais, disponíveis no acervo do Museu Municipal de Cachoeira do Sul, Olmira Leal de Oliveira era filha de Francisco José de Oliveira e Auta Coelho Leal. Pela fala de uma das narradoras, o pai era um dos homens de confiança nas tropas de Gumercindo Saraiva ${ }^{4}$ durante a Revolução Federalista, enquanto a mãe apenas circulava por este ambiente, não existindo indícios de seu papel social na guerra. Companheiros de casamento e de guerra, acompanharam Gumercindo Saraiva até a sua morte. Algumas narradoras, como Joana Galvão, contam ainda que os pais de Cabo Toco teriam encerrado as suas atividades após o sepultamento do líder maragato, antes disso, porém, contava Cabo Toco às narradoras que fizeram parte desta pesquisa que seus pais teriam ajudado a empalharar ${ }^{5}$ Gumercindo, deixando-o estático em cima do cavalo depois de morto, como uma forma de enganar o inimigo ${ }^{6}$.

A Revolução Federalista ocorreu entre os anos de 1893-1936. Os protagonistas do confronto foram líderes políticos do Rio Grande do Sul e Republicamos que estavam ao lado da República brasileira, que havia sido recém-proclamada. Os Gaúchos queriam autonomia e a liberdade do estado da governança federal. Dois grupos se formaram, os dos Maragatos, Federalistas que queriam a autonomia do Rio Grande do Sul e os Ximangos, ou pica-paus, do lado da República brasileira. Em 1923, os confrontos iniciaram-se novamente na tentativa de legitimar a eleição de Borges de Medeiros ao governo do estado do Rio Grande do Sul, o ximango Borges entraria no $5^{\circ}$ mandato. Apesar da reeleição continuada ser garantida por lei, seu opositor de urnas, o Federalista Assis Brasil, acusaria fraude na contagem dos votos, desencadeando o confronto.

Da união da guerra nasceu Olmira, aos dezoito dias do mês de junho de 1902, na cidade de Caçapava do Sul, Rio Grande do Sul. Nenhum relato conta quanto tempo viveu com seus pais, mas por meio das narrativas da enfermeira que a atendia em 1985, num consultório médico em Cachoeira do Sul, soubemos que sua infância foi permeada por causos 
contados pelo seu pai, que falavam sobre a guerra, sobre Gumercindo Saraiva e sobre o namoro que a mãe teria tido com o General Zeca Netto. Cabo Toco alimentou desde a infância um ódio ao maragato Zeca Netto, ao mesmo tempo que havia um apreço enorme por Gumercindo Saraiva. Ela contava com orgulho seu gosto pela guerra e a identificação com a postura do líder.

Segundo as informações do Museu Municipal de Cachoeira do Sul, aos 21 anos de idade, Olmira inscreveu-se no $1^{\circ}$ Regimento de Cavalaria para atuar como enfermeira durante o confronto armado de 1923. O regimento corresponderia ao que é hoje o $1^{\circ}$ Regimento de Polícia Montada, sediado em Santa Maria-RS. Ela atuava cuidando de feridos, dando-lhes medicações, fazendo curativos. Desde o seu ingresso na Brigada Militar mostrou interesse no manuseio de armas de fogo, principalmente com o intuito de se defender das ameaças masculinas de violência.

O curta metragem sobre Cabo Toco em "Histórias Extraordinárias" da Rede Brasil Sul de Televisão (RBSTV), emissora afiliada da Rede Globo na região Sul do Brasil, afirma que a transição de enfermeira a combatente ocorreu com o salvamento do comandante João Vargas de Souza, intendente de Caçapava do Sul, no confronto armado de suas tropas no combate do Passo das Pitangueiras em Caçapava do Sul no ano de 1924. Existem, ainda, relatos ${ }^{7}$ sobre o interesse de Olmira em participar da revolução. Olmira tinha o gosto pela guerra e vontade de vingança, queria a morte do General Zeca Netto. O namoro do General com sua mãe não teria acabado bem, Olmira o acusava de ter feito muito mal à sua família. Chica Papagaia, que conviveu com Cabo Toco no bairro Ponche Verde, afirma que quando perguntada sobre suas motivações para ir à guerra, Olmira respondia que foi porque era muito feia e não sabia realizar tarefas ditas "do lar", como cozinhar e cuidar de uma casa.

Com a ajuda que prestou ao comandante João Vargas de Souza, colocando-o em seu cavalo e levando-o até seu acampamento, Olmira tornou-se baioneta ${ }^{8}$ nas tropas, finalizando os inimigos. O termo escopeta também aparece quando as narrativas tratam do armamento usado por Cabo Toco, uma arma conhecida pelo seu uso na categoria de caça. No Rio Grande do Sul, o termo escopeta é pouco utilizado, sendo mais conhecida por espingarda, arma de cano liso e longo. Tal arma era um dos principais armamentos dos exércitos desde o final do século XVII. Cabo Toco era escopeta e baioneta, e tinha um grande conhecimento sobre manuseio de armas de fogo, na velhice dormia com um revólver calibre 38 embaixo do travesseiro' .

O comandante passou a chamá-la de Cabo, unindo o termo cabo a seu apelido Toco em virtude da sua baixa estatura. Daí Cabo Toco. Sua documentação, em documentos disponíveis no Museu Municipal de Cachoeira do Sul, apresenta lacunas a respeito de como ocorreu seu alistamento como Cabo, em virtude dos padrões de gênero impostos na época. Nos anos 1920, uma mulher alistada como combatente era 
considerado uma ofensa aos demais combatentes homens. O seu registro consta como Olimiro, encobrindo sua condição de mulher. Assim, tornou-se Cabo Toco um membro não oficial da Brigada Militar do Rio Grande do Sul. Sua efetivação constituiu-se como uma "farsa", segundo informações do Centro Histórico Coronel Pillar de Santa Maria-RS.

O episódio de guerra que marcou a perpetuação de Cabo Toco como heroína foi o de espionagem ao acampamento de seu maior inimigo, Zeca Netto, nas proximidades de Caçapava do Sul. O episódio configura-se como uma versão famosa dos feitos de Cabo Toco, e virou documentário, produzido e exibido pela $\mathrm{RBSTV}^{10}$ no ano de 2005 , que contou com elenco de protagonistas e figurantes da cidade de Cachoeira do Sul. O documentário da RBSTV foi baseado nas pesquisas de historiadores locais da cidade de Cachoeira do Sul, e ainda contou com a participação de intendentes da Brigada Militar do estado do Rio Grande do Sul, com relatos sobre a importância de Olmira na Revolução de 1923.

Cabo Toco teria o trabalho de espiã para as forças governistas no ano de 1926, infiltrando-se nas tropas do General Zeca Netto, proferindo o discurso de arrependimento e mudança de lado na revolução. Cabo Toco teria passado a noite no acampamento contrário a seus ideais, onde lhe ofereceram um banquete regado a churrasco, que teria evitado comer por medo de envenenamento. Cabo Toco não estava sozinha, alguns de seus companheiros estavam escondidos nas redondezas caso o plano de sondar o inimigo desse errado. Pela manhã do outro dia, a Brigada Militar atacou o acampamento, mas não teve sucesso na batalha. Em outra versão, contam que Zeca Netto e seus homens haviam pegado Cabo Toco, prendendo-a desacordada para ser arrastada por um cavalo, deixando-a com ferimentos graves.

A revolução terminou sem vencidos nem vencedores, com um acordo entre as partes na base militar da cidade de Pedras Altas-RS. Cabo Toco deixou a corporação apenas no ano de 1932.

Com o término das revoluções, Cabo Toco transitou pelas cidades de Bagé, Ijuí e São Sepé, todas no estado do Rio Grande do Sul. No ano de 1951, casou-se com Antônio Martins da Silva. O casal vivia fazendo fretes em São Sepé com uma carroça puxada a cavalo. Antônio Martins da Silva morreu no ano de 1954 e Cabo Toco mudou-se para Cachoeira do Sul-RS.

Em Cachoeira do Sul, passou a morar em um casebre no bairro Ponche Verde. A residência era um chalé de madeira, sem recursos hídricos e elétricos. Sobrevivia de fretes e de uma pensão do falecido marido, de Cz\$ 500,00 (quinhentos cruzados), moeda brasileira da época.

Certo dia, Cabo Toco recebeu uma oferta de um médico renomado da cidade de Cachoeira do Sul: trocar sua égua por um cavalo mais novo, para que pudesse dar ênfase aos serviços de frete. O médico levou seu animal e nunca apareceu com outro para troca. Dona Olmira ficou sem ter com o que trabalhar, dificultando mais ainda sua situação precária. 
Por volta do ano de 1985, em uma visita à igreja São José, Cabo Toco recebeu uma carona para sua casa no bairro Ponche Verde, a qual mudaria o rumo do final de sua vida. A pessoa que lhe oferecera a carona se chamava Vilma Zanini, era professora aposentada e vivia na cidade de Cachoeira do Sul. Gostava de escrever, ler e escutar histórias. Em um pequeno caderno, começou a anotar tudo que Cabo Toco lhe narrava sobre a vida. Tornaram-se amigas. Vilma tratou de tentar popularizar a história daquela heroína, organizando seminários sobre a revolução e conseguindo parceria com pessoas influentes. Cabo Toco passou a ocupar espaço entre as narrativas cachoeirenses, ganhou um soldo de $2^{\circ}$ Sargento da Brigada Militar e um aparelho de surdez. Passou a residir no Asilo Municipal Nossa Senhora Medianeira em Cachoeira do Sul.

Suas histórias se espalharam pelo Rio Grande do Sul. O encontro com Nilo Brum, compositor da música "Cabo Toco" ocorreu na mesma época do início da amizade com Vilma, em 1986. Numa ocasião em que precisou de cuidados médicos, Nilo Brum submeteu-se a uma operação em Nova Prata, sob os cuidados de um médico de quem já era amigo. Por coincidência, o médico era natural de Cachoeira do Sul, e durante as conversas com seu amigo-paciente, começou a falar sobre Cabo Toco. Interessado no assunto, Nilo Brum foi a Cachoeira do Sul procurar por Dona Olmira, para obter mais dados de sua vida. No dia 5 de maio de 1987 os jornais de Cachoeira do Sul anunciavam: "Cabo Toco ganhou a V Vigília ${ }^{11 "}$ ". Cabo Toco subiu ao palco e foi aplaudida de pé pela plateia, foi a primeira vez que um protagonista de canção subia ao palco:

Figura 1 - Caderno especial jornal Zero Hora - "Saia nas Trincheiras" (Porto Alegre-RS)

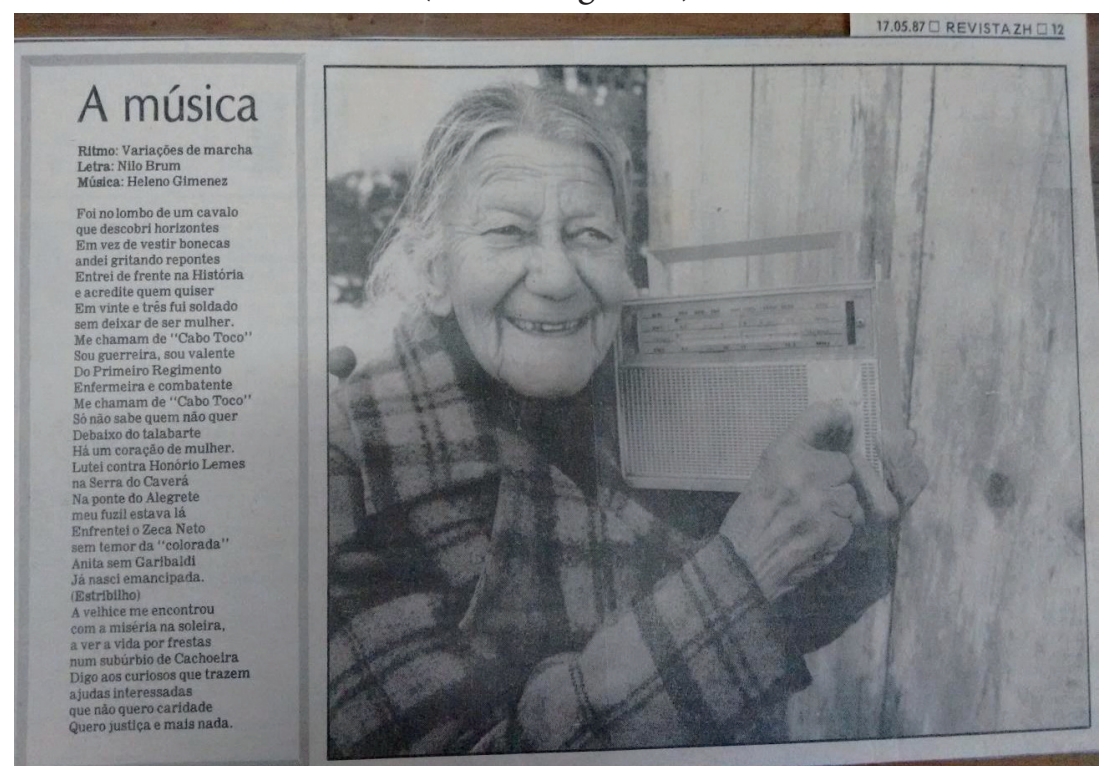

Fonte: Museu Municipal de Cachoeira do Sul - 08/09/2015

Cabo Toco morreu no dia 21 de outubro 1989, aos 87 anos. Depois da premiação da Vigília do Canto Gaúcho, passou por tratamento mé- 
dico em função de uma doença crônica no pulmão, que acabou provocando sua morte, pois a doença de Dona Olmira era terminal. Ela havia sido internada no Hospital da Brigada Militar, em Porto Alegre ,durante um mês, recebeu alta e foi novamente internada, no Hospital de Caridade e Beneficência de Cachoeira do Sul, quando veio a falecer. Olmira Leal de Oliveira foi velada no Asilo Nossa Senhora Medianeira, e sepultada no dia 22 de outubro no Cemitério Municipal de Caçapava do Sul, junto ao seu esposo.

\section{Figura 2: Túmulo de Cabo Toco e esposo em Caçapava do Sul}

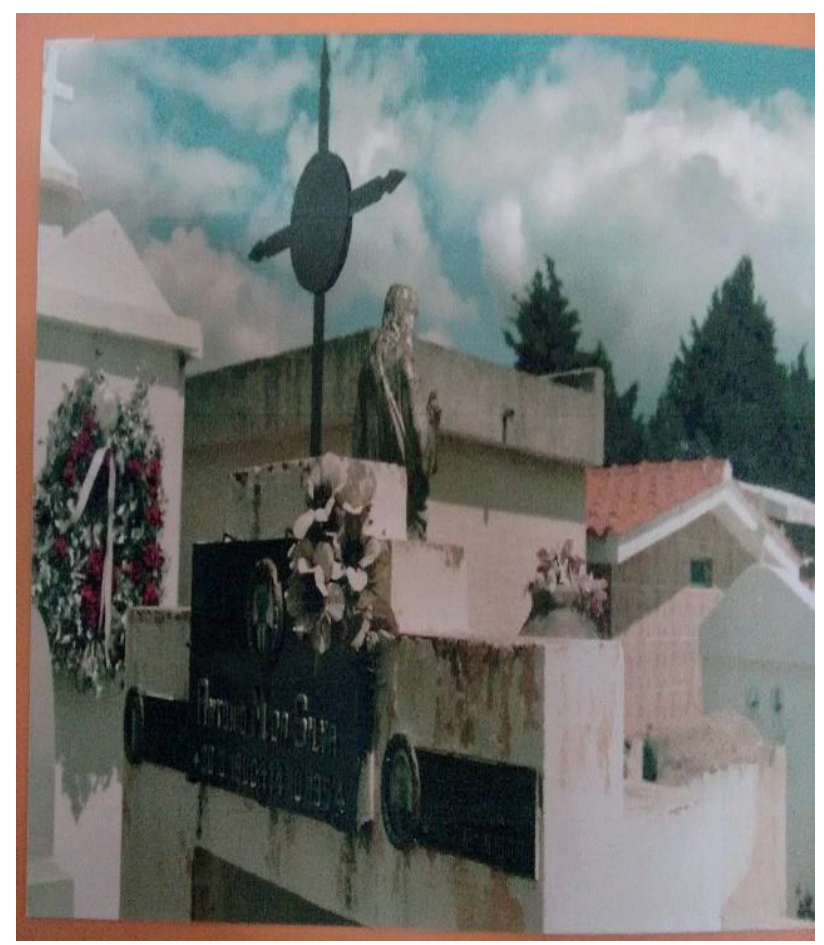

Fonte: Museu Municipal de Cachoeira do Sul - 08/09/2015

Após sua morte, Cabo Toco foi homenageada em diferentes seguimentos no estado do Rio Grande do Sul, tornou-se nome de rua em Cachoeira do Sul, Caçapava do Sul e Ijuí. Passou a nomear o Centro de Tradições Gaúchas (CTG) do 9º Batalhão da Polícia Militar em Ijuí, um Piquete $^{12}$ em Esteio e a primeira turma de policiais femininas do Rio Grande do Sul.

\section{CABO TOCO E O TRADICIONALISMO GAÚCHO}

Para pensar a história das mulheres e os contornos míticos que adquire a figura feminina no Rio Grande do Sul, nos moldes sugeridos pelo Movimento Tradicionalista Gaúcho, selecionamos alguns fragmentos que demonstram um teor ideológico do papel das mulheres e seus atributos na construção da história gaúcha: 
O Rio Grande do Sul é um estado caracterizado pela fibra de suas mulheres. Muitas delas destacam-se em vários âmbitos da sociedade brasileira. Esta bagagem é trazida desde a ocupação do estado, no jesuitismo, tropeirismo, estanciamento, revoluções, imigrações e atualidade. A primeira mulher gaúcha era tupi-guarani. Nômade, cuidava dos filhos e acompanhava os índios. Com a chegada jesuítica, nas primeiras Missões, elas aprimoraram suas técnicas no artesanato, trabalhavam nas lavouras e eram catequizadas. A grande qualidade de quantidade de índios catequizados chamou a atenção dos bandeirantes (homens que organizam bandeiras e caçadas aos índios) estes que começaram a escravizá-los. Isso acabou despertando pavor entre os silvícolas e missionários, estes que fugiram para outro lado do rio Uruguai. Assim, o Estado ficou novamente abandonado por quarenta anos; até que chegaram aqui os Jesuítas Inacianos Espanhóis comandados pelo Padre Roque Gonzáles, da banda oriental do rio Uruguai, trazendo novamente o gado orelhano e reduzindo os dezoito aldeamentos para Sete Povos. Retrocedendo um pouco se pergunta: - O que aconteceu com esta "terra de ninguém" durante tanto tempo? Os bandeirantes possuíam as índias e levavam os índios como escravos. Depois que nasciam tais crianças, notavam que elas estavam sem identidade: metade selvagem e a outra, branco. Eles não se acostumavam com a vida das tribos muito menos com a vida dos brancos. Muitas das vezes tais "frutos" iam vagueando pelos campos, como vagabundos, sem pátria. E assim foi surgindo o gaúcho. O Pe. Roque Gonzáles reiniciou então o missionarismo criando gado. Como o couro era bem visado, começaram as tropeadas até Sorocaba (São Paulo). Os homens responsáveis por recrutar, eram chamados de tropeiros. Sempre que chegavam em São Paulo, eles arranjavam suas companheiras que eram encontradas nos arredutos. Elas eram de vida fácil, queriam conhecer o mundo, as chamadas "mozuelas". Na maioria das vezes, os tropeiros as deixavam por aqui, para cuidas das próprias famílias que estavam formando. Começavam a formar estâncias para a pastagem de gado e fixação do homem da terra. A mulher era geralmente a chefe do lar. Cuidava da educação dos filhos e dos afazeres domésticos. É importante ressaltar o papel da mãe, pois o pai cuidava do gado e do serviço pesado. A família era unida e havia liberdade entre todos. Nas grandes sociedades, as meninas eram preparadas para serem verdadeiras damas a fim de casarem-se com homens de classe, jamais elas participavam das reuniões em que homens estivessem presentes. No campo, o sistema era diferente, as mulheres podiam fazer parte de uma roda de chimarrão e ouvir os causos. Isto já caracterizava uma certa independência da liberdade da mulher gaúcha dentro de sua própria família. As revoluções começavam a estourar, os maridos e os filhos mais velhos deixavam suas casas sem saber se voltariam. Mais um suplício: mulheres sozinhas em seus ranchos empunhavam armas e se transformavam em guardiãs do lar. Nascia em seus corações a esperança de rever seus amores e de que um dia a paz retornaria. Aqui o papel de mãe acentuou-se cada vez mais pois, além de educar, ela tinha todo o serviço masculino, inclusive a proteção ao que possuía. Aumentada a necessidade de povoamento, iniciava-se a chegada dos imigrantes alemães, italianos e assim por diante. 
Seus costumes eram diferentes, a grande religiosidade, as diferenças familiares entre homens e mulheres..., enfim, houve uma troca de culturas: os imigrantes coivara e bebendo chimarrão e os gaúchos tocando a gaita jogando bocha. Nestas mudanças, o papel da mulher foi muito importante, porque ela estava sempre ao lado do homem e mesmo que este se ausentasse, ela continuava sem maiores problemas, com a fibra de ser guerreira na luta pelos seus direitos e pela preservação dos costumes, da honra e do seu orgulho (REVISTA TEMPO, [s.d.]).

Durante o processo de pesquisa, no que se refere aos arquivos jornalísticos encontrados, a percepção preponderante é de uma heroína esquecida. Assim, pelo teor do esquecimento, as manchetes de jornais tinham o intuito de causar um efeito de comoção. Uma percepção que pudesse ser concebida e entendida de maneira imediata à leitura, formando uma opinião acessível. A intensão da documentação de jornal é informar sobre o mito, porém de maneira diferente das epopeias clássicas que evidenciam heróis, narrativas históricas que justificam acontecimentos.

Augé (1998) afirma que é preciso esquecer para continuar presente, esquecer para não morrer, esquecer para permanecer fiel. Quando se esquece de recordar, ou ainda, recorda-se pelo discurso do esquecimento, a carência de lembrança ganha outros sentidos. Assim, o esquecimento, em suma, é a força viva da memória e a recordação em seu produto (AUGÉ, 1998, p. 27). Ao tratar Cabo Toco de maneira a evidenciar o seu heroísmo esquecido, a documentação afirma e reafirma a mulher que não se encaixa nos padrões dos heróis gaúchos que protagonizaram a história do Rio Grande do Sul, mas que passa a ser heroína a partir do momento que se tem um interesse de pessoas de fora do contexto da cidade de Cachoeira do Sul, por ritualizá-la. O esquecimento aqui cumpre uma função pedagógica da memória, exercendo a manutenção do tempo presente, remetendo à dimensão da experiência circunscrita na vida de Cabo Toco.

Segundo Renan (1887), o esquecimento é um fato essencial para a criação de uma nação, seja ela local ou extensiva ao nacional, pois ele garante o caráter de continuidade das identidades, reforçando a composição da memória elaborada pelos mortos, que deve ser mantida pelos vivos através do desejo de viver junto, numa grande solidariedade construída pelo sentimento de sacrifício daqueles que viveram no passado, como grandes homens que lutaram e tornaram-se heróis. A lembrança pelo esquecimento em Cabo Toco garante a manutenção das coisas em comum, que devem ser essenciais para as identidades, principalmente a do gaúcho, homem guerreiro, desbravador de territórios.

O fragmento introduzido, sobre "A mítica das mulheres heroínas", conduz a uma ilustração para uma possível tradução do pensamento social. A partir do trecho, é possível pensar em representações das mulheres na formação do estado do Rio Grande do Sul, em suas "liberdades" e a necessidade de manutenção do lar, enquanto seus esposos, os heróis de guerra, estão ausentes. 
O texto nos faz pensar na figura de heróis históricos, entendidos culturalmente como aqueles responsáveis pela formação de uma identidade local, e que, em seu estilo de vida, refletem o "dever-ser". Segundo Brum (2009), o gaúcho, em sua tradição histórica como herói, é fundado para simbolizar, como emblema, a saga da domesticação do território através da exaltação da bravura de sua dupla atuação como homem do campo e guerreiro. A figura que é exaltada, quando os tradicionalistas falam no Rio Grande do Sul, é sempre a masculina, deixando a mulher em papel subalterno nos afazeres de casa (OLIVEN, 1990).

Cabo Toco é citada pela Revista Tempo 16 ao lado de Anita Garibaldi. Para as duas o adjetivo "prostituta de guerra" foi dado. Como Anita dispusera-se à guerra por acompanhar seu amado Giuseppe, a ela o adjetivo foi dado no sentido de estar presente em muitos confrontos armados; já para Cabo Toco o termo "prostituta de guerra" é elencado de maneira pejorativa, indicando que Cabo Toco dormia com os inimigos para que suas tropas vencessem as batalhas. "Cabo Toco teria feito tudo isso por ideais ou submissão?”, questiona a reportagem da revista.

A "natureza" feminina da mulher gaúcha, expressão popular que figura diferentes espaços, pode ser explicada pela atribuição do espaço doméstico como algo de natureza feminina, e os espaços públicos (a cultura) como da ordem do masculino (ORTNER, 1979). A mulher estaria definida enquanto natureza pela função de seu corpo e estrutura psíquica, pelo seu envolvimento com a procriação e papel social que estaria designada a desenvolver, o qual seria inferior ao masculino, pois o homem poderia atuar de modo livre, mudando a natureza conforme seus interesses. O corpo do homem estaria mais próximo da cultura (ORTNER, 1979), assim como a guerra estaria mais próxima dos dois.

A definição de que as mulheres correspondem ao âmbito da natureza e a ideia de que os homens estão mais próximos da cultura caracteriza a cultura como um lugar de experiências e agências. $O$ que não necessita de agência para ocorrer, resta para a natureza. Durante as revoluções, no que diz respeito à sua história, as mulheres sofreram forte reprovação em relação à sua presença em espaços públicos, os quais não seriam apropriados à sua natureza; assim, elas foram menosprezadas e seu comportamento considerado ridículo e inadequado (TILLY, 1994).

De fato, o heroísmo e liberdade que cabe às mulheres no Rio Grande do Sul, como revela "sua mítica" na Revista Tempo 16, é poder ouvir as histórias na roda de mate, e está na capacidade de defender sua família de punho armado, zelando por sua honra na ausência do marido. Para Neto (2009), o gaúcho é um tipo social humano que tem sua origem no povoamento do sul da América pelo homem branco descendente de europeus. O autor afirma que o mito cunhado sobre a figura do gaúcho está na representação do passado que existiu dentro de um tempo determinado, no presente: 
Sua constituição se deu desde meados do século XVII, com a colonização branca, até metade do século XX com a modernização agrária sul-brasileira, promovida pela industrialização e a urbanização, com todos os seus desdobramentos. Este intervalo de tempo que compreende pouco mais de três séculos sedimentou a cultura e a etnicidade do gaúcho. Sobre este passado se produziu uma identidade e sobre esta identidade se produz, hoje e desde então, representações sobre um passado mitificado, heroicizado, e idealizado num mito de origem (NETO, 2009, p. 13).

Criou-se, portanto, uma tradição cunhada pela representação do gaúcho herói, pioneiro de um território, que passou a ser entendido como identidade, e sobre ela elaborou-se uma estrutura. A estrutura dos grupos está na maneira como os fenômenos sociais agem nos agrupamentos e, no caso do heroísmo no Rio Grande do Sul, a estrutura está circunscrita à imagem do homem do campo, que se configura como guerreiro que conquistou seu território, para que este fosse propenso à educação de iguais a si, construindo um lar e tendo filhos que fossem educados pelo conceito de heroísmo, garantindo a estrutura. As estruturas são fundadas num tipo ideal, prescrevem e assimilam circunstâncias, negando seu caráter contingente. Existe uma ordem que projeta o existente numa repetição, reproduzindo-se mesmo quando há mudanças sociais (SAHLINS, 2003).

Figura 3 - Charge "A heroína”, Jornal do Povo (Cachoeira do Sul-RS)

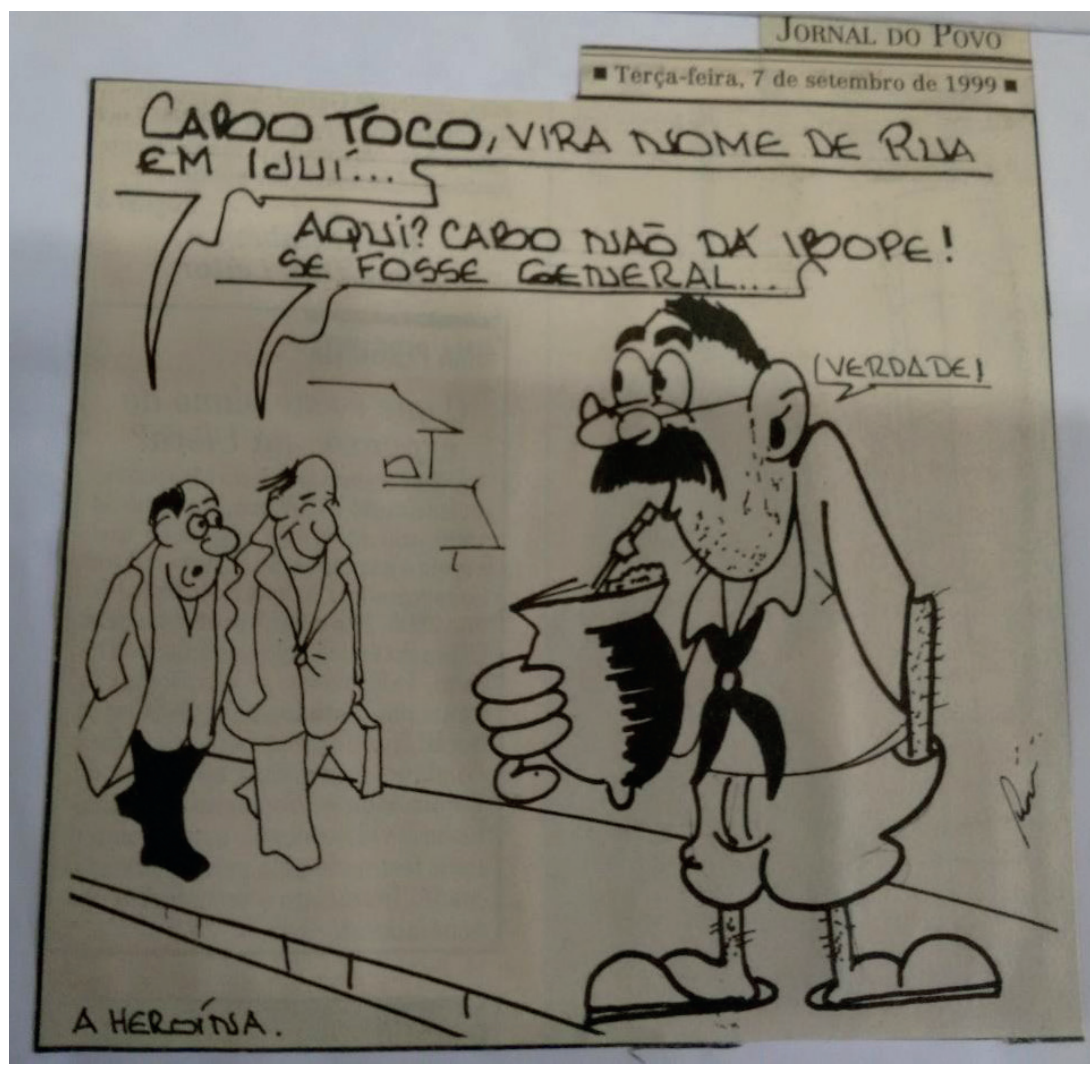

Fonte: Museu Municipal de Cachoeira do Sul - 08/09/2015 
Os jornais retrataram Cabo Toco tal como ela foi retratada pelo tradicionalismo. Esta apresentação resultou em uma ação comunicativa da imprensa não só de informar, mas de focar em ideias e reproduzi-las, convocando à análise etnográfica de percepções de mundo e julgamento. A lembrança de Cabo Toco pelo esquecimento é uma maneira usada pelos jornais para informar pela culpa, ainda que fosse numa tentativa de reversão. A apelativa do senso comum foi redigida em muitas páginas, colocando em questão até mesmo a veracidade da participação de Cabo Toco na revolução. "A Cabo que não dava ibope", conforme ilustra a charge "A heroína”, evoca, em um simples desenho, os estereótipos que Cabo Toco carregou, e que ainda foram reproduzidos pela documentação jornalística, guiando a necessidade do esquecimento.

Para além de um ideal de heroísmo, há um ideal de ser mulher a partir de padrões específicos, conforme explica Prado (1981) em seu artigo "Um ideal de mulher: estudos dos romances de M. Delly". Assim, todas deveriam agir da mesma forma em relação ao seu comportamento. Por intermédio das revistas, eram condicionadas a aprender a ser mulher, e mesmo quando apareciam no papel de heroínas nos folhetins, não poderiam ter grandes ambições, deveriam sempre estar em posição de dependência, corresponder aos padrões de beleza de cada época e ainda teriam de ser jovens (PRADO, 1981).

O esquecimento sobre Cabo Toco e, ainda, sua lembrança pelo esquecimento, formam contextos necessários para induzir um conceito de leitura, que se apresentam em oposição ao mesmo tempo que se conectam. Compreendemos que a configuração de heroína feminina no Rio Grande do Sul, neste sentido, pontua-se por disputas simbólicas entre história, tradição e atores sociais (BOURDIEU, 1989). Ao contrariar a tradição dos heróis, Cabo Toco mudaria sua relação com seu reconhecimento, diante de uma estrutura fundada sobre um tipo ideal de heroísmo e sobre um tipo ideal de mulher.

Não concordar com o que estava dado por escrito passou a ser rotina na vida de quem conheceu Cabo Toco. Inconformadas com o esquecimento, as narradoras, apesar de guardarem consigo muitos recortes de jornais, passaram a tentar reverter a situação, partindo para estratégias que pudessem dar conta dos feitos de Cabo Toco. Havia uma memória em disputa, bem como uma reflexividade em jogo, ligadas a determinadas concepções do tempo e suas consequências em termos da reprodução e da mudança social.

\section{APRENDENDO SOBRE CABO TOCO: IDENTIDADES E RECIPROCIDADES}

Na introdução de "Ilhas da História", Marshall Sahlins (2003) argumenta sobre a circulação da história, que em contextos antropológicos determinaria como os grupos organizaram-se dentro de uma tessitura concebida como cultura. A história seria a cultura num esquema de 
significações diferentes, e vice-versa, na qual se moldaria conforme o exercício de sua realização, nas ações criativas dos sujeitos históricos e sua organização diante de uma cultura preexistente (SAHLINS, 2003).

As narrativas sobre Cabo Toco se constituem em possibilidades pedagógicas para os grupos em suas práticas. Elas têm o intuito de explicar comportamentos elaborados por uma aprendizagem. As narrativas têm caráter legitimador de ações e agências, que reforçam a discussão e elaboração de questões sobre a função pedagógica da memória.

A intencionalidade do contar, para além da produção e reprodução de conhecimento, é uma característica fundamental para a compreensão das relações com as narrativas sobre Cabo Toco. A memória, em seu caráter pedagógico, formula uma agência feminina criada diante das relações de poder e processos de subjetividade que, em termos de valores diferenciados e hierárquicos, garantem uma dinâmica de contra hegemonia de práticas (ORTNER, 1990). São estágios que revertem relações, e são produzidas por afeto ou solidariedade, poder ou rivalidade, e atuam de maneira a influenciar os indivíduos a pensarem para além de uma estrutura (ORTNER, 2006). Neste sentido, a narrativa de Cabo Toco propõe-se a pensar em acontecimentos que mantêm vivas as oralidades (mesmo que em diferentes conotações e ensinamentos), as quais determinam segmentos de aprendizado para a vida, estejam essas pautadas pelas tradições gaúchas ou pela tentativa de revertê-las.

Em seu contexto particular, as narradoras, ao contarem sobre Cabo Toco, exaltaram sua vontade e interesse em participar da pesquisa, formando um leque de possibilidades a partir dos primeiros contatos. Aqui a palavra interesse vai além do narrar propriamente dito, pois elas procuram ensinar o que sabem e aprender com outros relatos, buscando informações. Propõem-se a pesquisar não só como uma atitude de ajudar a compor as diferentes vozes dessa etnografia, mas de maneira a garantir um conhecimento a mais sobre Cabo Toco para si mesmas.

Ao colaborarem com os subsídios de pesquisa, trouxeram outras narrativas que acabaram tornando outras vozes visíveis. Elas interpretaram suas próprias falas e a representação que circunda a figura de Cabo Toco. Conhecer sobre Cabo Toco, para estas mulheres, é uma maneira de legitimar a afeição que elas têm a Dona Olmira. Para além de representar Cabo Toco, representam a si mesmas, vendo-se em Cabo Toco.

$\mathrm{Na}$ verdade, eu não sei contar muito sobre a história dela, os detalhes, sobre o que aconteceu realmente. Ela morava no Bairro Ponche Verde, começou a aparecer nos jornais e despertar a curiosidade da gente. Quando saiu a música todos comentavam sobre, não pela música em si, mas pela história de vida. O sofrimento que ela carregava era evidente, pela velhice, o abandono, mas aquilo ao mesmo tempo despertava conhecer os motivos de tudo. Ela rompeu com os padrões de uma época, apesar de ela ter sido colocada como homem nos papeis oficiais, eu acho que ela sabia que um dia seria reconhecida como mulher guerreira, e é isso que eu carrego para mim e tenho interesse de contar para os outros (JOANA GALVÃO, 26 out. 2015). 
Procuro sempre me informar sobre as exposições que tem no museu sobre ela, gosto de ir lá ver o que tem sobre, às vezes são as mesmas coisas, objetos no caso, mas o enfoque que o pessoal dá é sempre diferente. Para mim é uma honra ela ter escolhido Cachoeira para passar o resto da vida, eu morei no Bairro Ponche Verde, eu era pequena e a gente via ela, carregando as mercadorias do pessoal que comprava no mercadinho do bairro na carroça. Depois quando ela foi morar no asilo eu já estava grande, já estava acabando o curso normal, lembro que quando saiu a música tivemos uma aula sobre isso, mas eu não me lembro direito quem era o professor. Aquilo foi importante porque eu passei a entender que a história dela era importante de ser passada (ANITA GARIBALDI, 09 set. 2015).

Quando a gente era pequena, eu e minha irmã, meu pai tinha um armazém no bairro Ponche Verde e ela ia lá comprar algumas coisas. A gente nunca entendeu quem era aquela mulher com nome de homem, a gente morria de medo e se escondia. Coisa de criança, né? Mas a gente morria de medo! Para mim ela era uma heroína, porque fazer o que ela fez e naquela época. Deve de ter passado por muita coisa, ainda mais vivendo com um monte de homem. Eu me inspiro muito nela, na coragem que ela teve, apesar de saber que ela morreu aqui pobre, pouca gente sabia quem era ela. Depois de grande que eu fui entender o significado que ela tinha, eu acredito na importância que ela tenha não só para a cidade, mas para as mulheres daqui. Foi uma porta que se abriu através dela para todos verem que as mulheres são guerreiras, não só para os homens verem, mas para as próprias mulheres verem que podem tudo (CHICA PAPAGAIA, 29 abr. 2015).

A Cabo Toco parecia duas pessoas diferentes, mas não são. Tem muita gente que pensa que ela é só uma música, mas para nós que conhecíamos ela antes da Vigília, ela é uma heroína. Por muitos anos viveu como miserável, doente, passando necessidades em Cachoeira e sem ser reconhecida por ninguém. Viveu a penúria e revoltada como uma velha ranzinza, uma imagem meio ruim para quem defendeu nosso chão com muita fibra e coragem deixando muitos homens envergonhados. Aí virou heroína antes de morrer, só por causa da música? Eu acho que não, porque ela não precisa ser a heroína de todo mundo, só para a gente que sempre viu o que ela representava está bom, não precisa de quantidade, mas de qualidade (FRUTUOSA DA SILVA, 22 set. 2015).

A escrita etnográfica aqui enfoca a múltipla experiência de pessoas que têm a intenção de tomar para si a narrativa sobre Cabo Toco, colocando-a como heroína digna da afeição do grupo, elaborando com outras significações a memória que foi elaborada pela documentação etnografada nos jornais. As múltiplas vozes formulam um argumento polifônico, que foi construído pela permissão do diálogo aberto, dando conta de diversas frações envolvidas na representação de Cabo Toco, que consequentemente contribuíram para a perpetuação de uma oralidade e de uma virada histórica. 
O jogo de vozes estabelecido e suas relações ressalta as questões empíricas que permeiam as vidas dessas mulheres que narram, sua necessidade de reformular categorias e de ensinar e aprender sobre Cabo Toco. A partir do momento que tomam a história de Cabo Toco para si, o que é levado em consideração são suas ações, e não mais uma estrutura que julga o que é concebível ou não, é a transformação criativa que prevê uma finalidade, os indivíduos têm autonomia sobre sua cultura e sobre a reversão de estigmas históricos (SAHLINS, 2003).

Ao contar sobre Dona Olmira numa mistura de si, dentro do processo autobiográfico em forma de narrativa oral, correntes de histórias foram surgindo, as quais retratam a vida, a infância e a memória sobre diversas formas de aprendizado pedagógico (PINEAU, 2006, p. 41). São narrativas de experiências em que se definem e personificam-se figuras, saberes e afeições, numa competência reflexiva sobre quem foi Cabo Toco e sua importância para a memória e para o município de Cachoeira do Sul.

As narrativas são marcadas pelo empoderamento de mulheres que performatizam, em suas falas, suas agências, promovendo seu prestígio enquanto intelectuais e acerca de diferentes saberes sobre Cabo Toco. Contar sobre Cabo Toco coloca essas mulheres numa esfera pública, deslocando-as do aprendizado vivido na infância e restrito ao privado, ou seja, levando informações sobre Cabo Toco para fora de suas casas e, assim, produzindo um referencial sobre o método de contar, colocando-se num lugar privilegiado no âmbito do saber.

As marcas simbólicas sobre narrar sobre Cabo Toco no âmbito público compreendem subjetividades ligadas à vida cotidiana em seus discursos e significados, em que a narrativa gera uma expectativa social de experimentação do conhecimento sobre Cabo Toco, naquilo que ela representa para as agentes. Há uma perspectiva de recepção dessas oralidades; quem ouve também carrega uma bagagem narrativa e versões sobre os fatos que, no jogo do contar e receber elementos sobre Cabo Toco, transformam-se, unem-se, gerando questionamentos diante de acontecimentos, lugares e pessoas. São visões de mundo que conduzem a forma do narrar, por meio da construção social do mundo vivido, de imaginários e elementos históricos.

Por meio de ensinar e aprender as narrativas, concretizam-se pensamentos e ideais em forma de transposição, colocando significações sobre a vida de Cabo Toco e sentidos que evocam uma visão consciente sobre descobertas de fantasias, que retomam a infância, sobre como começa o entendimento da linguagem do que é ser uma mulher num ambiente de guerra, evocando o folclore nas mais diversas formas do narrar no Rio Grande do Sul. São falas que propõem experiências não só imaginadas, mas imagináveis, a quem escuta, numa capacidade comunicativa, em que a etnografia se torna uma construção de memórias partilhadas. As narrativas são quase que poéticas, pois retratam diferen- 
tes pessoas e vidas na figura de Cabo Toco, adicionam lugares-comuns e deslumbram caminhos.

O compartilhamento de memórias exercido pelas mulheres também é um instrumento político focado em artefatos, testemunhos, histórias, experiências, situações e ações individuais ou coletivas, tornando-as protagonistas junto a Cabo Toco: de narrativas sobre aprendizagem vividas em suas várias expressões. Assim, unidas pela oralidade, estabelecem a manutenção da memória sobre Cabo Toco, e ainda sobre si próprias, orientando estratégias que sejam culturalmente significativas para a resistência da narrativa.

\section{CONSIDERAÇÕES FINAIS}

Dentre aquilo que chamou atenção nos diferentes contextos e falas de mulheres que narram sobre Cabo Toco, a prerrogativa do sofrimento é uma constante. Sendo este uma forma de resistência aos padrões impostos pelo "ser mulher". Ora, se você não aceitar aquilo que lhe é imposto, sofrer é inevitável. O papel das mulheres, nos espaços de guerra, era o de prostituta ou enfermeira. Ambos envolviam a lógica do cuidado, o corpo da mulher e, ainda, ao espaço privado, onde se atendiam as "necessidades" dos homens. Os personagens femininos nas histórias são passivos, na categoria de mocinhas. Quando são más ou ativas, são sujeitas a castigos terríveis, e são fadadas a não fazerem a passagem de menina para mulher, ou seja, casar-se. Os personagens ativos nas histórias são os homens, assim, um lado depende do outro para concretizar sua agência (ORTNER, 2006). Cabo Toco desafiou sua condição socialmente dada de mulher na guerra, e ainda foi ativa por tomar para si atitudes que poderiam ser feitas apenas por homens, estabelecendo a partir dali um marco para seu processo de reconhecimento enquanto heroína/mulher e seus balizamentos entre esquecimento e empoderamento.

Cabo Toco possui uma força social que determina sua resistência (ORTNER, 2006), exercendo função pedagógica em direção ao processo de aprendizagem coletivo que envolve mulheres que tomam para si a luta pelo prestígio de Cabo Toco, construindo a cada narrativa um novo saber e novas subjetividades. As narrativas autobiográficas são demarcadas por diferentes saberes, elaborando o sentido da memória em diferentes variáveis, como faixa etária, nível de estudo e participação política, que interferem nos modos de repercussão do passado (SOUZA, 1996).

A agência, aqui exercida por diferentes mulheres, é uma composição de saber e conhecer, de forma mútua, o poder sobre a narrativa de Cabo Toco. Segundo Ricoeur (2007), a glória mútua, colocada sob tutela da relação de reciprocidade, passa pelo reconhecimento de si na variedade das capacidades que modulam seu poder de agir (RICOUER, 2007). Assim, as menções a Cabo Toco nas trajetórias de vida contadas pelas narradoras são autobiografias que dão vida ao passado no presente, ofe- 
recendo competência às relações, e simbolizando identidades nas quais os laços sociais são atados (RICOUER, 2007).

Saliente-se que, mesmo unidas em prol de um ideal, as narradoras em suas agências estão longe de constituir um grupo homogêneo. São pessoas diferentes que possuem intenções diferentes, mesmo que narrem sobre os mesmos assuntos, formando toda espécie de transposições criativas e variando intensamente de um mundo social para outro (SEWELL apud ORTNER, 2006, p. 54). Portanto, o percurso conduz diferentes vozes ligadas pelo contar sobre si e sobre Cabo Toco, construindo contextos que levam diferentes vidas a serem interpretadas perante as experiências de Cabo Toco. De modo que aprender sobre Cabo Toco torna possível uma agência pedagógica de habitar o mundo e construir-se como pessoa, unindo realidades, contextos e influências da vida cotidiana. A agência pedagógica criada por estas mulheres não se resume apenas à transmissão de informações, mas às suas capacidades, competências e saberes tradicionais, categorizados como habilidades traçadas pelas gerações anteriores. São subsídios que norteiam a cognição e atenção educativa (INGOLD, 2010), uma vez que o narrar constrói orientações de um caminho para conhecer sobre a Cabo Toco do passado, tornando-a parte do tempo presente de cada narradora.

As agências femininas nas experiências de compreender Cabo Toco ao longo do percurso etnográfico demostraram um aprendizado pedagógico elaborado pelas narrativas, não bastando apenas ouvir, mas perceber cognitivamente o que aqueles relatos estavam querendo dizer, tanto sobre Cabo Toco como sobre as mulheres em suas autobiografias. As autobiografias, em sua oralidade, concebem reflexos do passado no presente, a partir de experiências e visões de mundo, em que a memória ecoa por ressignificações e agenciamentos, partindo de Cabo Toco e suas narrativas como um modo de viver. Cabe sinalizar que as narrativas e narradoras desta etnografia mostraram, através de suas sabedorias e técnicas, suas relações cotidianas, que se mesclavam à vida de Cabo Toco. Os dispositivos criados, intencionais ou não, articulam-se em prol da resistência de uma narrativa que mantém suas identidades de guerreiras, assim como Dona Olmira que apenas queria reconhecimento $e$ mais nada.

Para finalizar, é preciso ainda evidenciar algumas questões relativas aos homens envolvidos nas narrativas, denunciadas pelas narradoras ao longo do percurso etnográfico: Edir, que era médico e amigo do compositor, "roubou" um cavalo e virou nome de museu; Cabo Toco nunca recebeu um centavo pelo prêmio da canção. Afirmam as narradoras que teria sido a própria Cabo Toco a autora da canção e que hoje o valor da premiação equivaleria a 15 mil reais. A equipe de um cineasta gaúcho que queria tornar a vida de Cabo Toco um filme, ao ler o texto de dissertação apresentado ao Programa de Pós-Graduação em Ciências Sociais não suportou a hipótese de que seu ídolo, Zeca Neto, poderia ter 
feito algum mal a mulheres na época da Revolução. Para a construção etnográfica recorreu-se a algumas entidades ligadas à história da Brigada Militar do Rio Grande do Sul e, quando não houve omissão, afirmaram que os registros de Cabo Toco eram uma fraude. Por fim, mas não menos importante, historiadores -homens - de Cachoeira do Sul acreditam serem mentiras as narrativas em circulação sobre Cabo Toco.

Negar assegura uma dimensão higienizada da história, em que narrar o passado incomoda.

\section{NOTAS}

1. Toda documentação acessada não possui cota (etiqueta na lombada dos documentos).

2. Giuseppe Garibaldi (1807-1882) foi um militar e guerrilheiro italiano. Participou do movimento nacionalista "Jovem Itália", que pretendia a unificação de toda a península sob a forma de república. Exilado no Brasil, participou da "Guerra dos Farrapos" e lutou na guerra entre a Argentina e o Uruguai.

3. David José Martins, conhecido como David Canabarro e chamado de General Canabarro (Taquari, 22 de agosto de 1796 - Santana do Livramento, 12 de abril de 1867) foi um militar brasileiro e um dos líderes da Revolução Farroupilha.

4. Gumercindo Saraiva (Arroio Grande, Rio Grande do Sul, 13 de janeiro de 1852 - Carovi, Capão do Cipó, Rio Grande do Sul, 10 de agosto de 1894) foi um militar brasileiro, sendo um dos comandantes das tropas rebeldes (maragatos) durante a Revolução Federalista.

5. A taxidermia - nome técnico do empalhamento de animais - é um sofisticado processo em que só a pele do animal é aproveitada. O couro é usado para "vestir" um manequim de poliuretano, parecido com esses que a gente vê nas vitrines de lojas. No passado, porém, não era assim. $\mathrm{O}$ animal era aberto, suas vísceras retiradas e, no lugar delas, era colocado algodão, juta ou palha - daí a palavra empalhamento, hoje fora de uso.

6. Informação concedidas por Joana Galvão em entrevista no dia 26/10/2015.

7. Como os de Frutuosa da Silva em 22/09/2015 e Joana Galvão em 26/10/2015.

8. Terno designado a soldados de infantaria - arma branca pontuda que se adapta ao extremo do cano de fuzil ou espingarda, usada por soldados de infantaria em combates corpo a corpo.

9. Informações concedidas pela própria Cabo Toco em entrevista para o Museu da Brigada Militar. Documento disponível no Museu Municipal de Cachoeira do Sul. 10. A RBS TV é a maior rede de televisão regional brasileira. A sede principal da empresa fica em Porto Alegre, capital do Rio Grande do Sul, e suas emissoras e retransmissoras cobrem a totalidade dos estados do Rio Grande do Sul e de Santa Catarina. 11. A Vigília do Canto Gaúcho é um festival de música nativista, considerado como um dos eventos culturais mais importantes da região central do Rio Grande do Sul. Nasceu no ano de 1982 em Cachoeira do Sul, sendo responsável, no decorrer de 24 edições, pelo lançamento de vários grupos musicais, cantores individuais, letristas e musicistas, bem como pelo fomento à cultura musical do estado, além de garantir atenção permanente da comunidade cultural do estado e do público em geral. 
12. Segundo Jesus (2015), tanto o CTG quando o Piquete são entidades caracterizadas conforme o Regulamento Geral do Movimento Tradicionalista Gaúcho (MTG) como sociedade civil, de fins não econômicos, com um número mínimo de sócios, a depender do perfil da entidade, e estruturada "de acordo com a forma adotada nas origens do Movimento Tradicionalista Gaúcho", aplicando em seu âmbito associativo e na sua área de influência (região tradicionalista) os princípios e objetivos do Movimento, descritos na chamada "Carta de Princípios" (disponível em: <https://www.mtg.org.br/carta-de-principios/>) e que relacionam-se com os valores regionais, com padrões de moralidade e com a produção de uma "unidade psicológica" a partir das entidades (MTG apud JESUS, 2015). Ainda de acordo com o regulamento do MTG (1961 apud JESUS, 2015), o CTG é uma entidade de participação plena no movimento, que deve seguir à risca todas as normas previstas da Carta de princípios da entidade. Já o Piquete configura-se como um lugar menor, mais popular e que pode ou não ser filiado ao MTG. Em seu significado literal, conota o sentido de pequeno potreiro, ao lado da casa, onde se põe ao pasto os animais utilizados diariamente.

\section{REFERÊNCIAS}

AUGÉ, Marc. A guerra dos sonhos. Oeiras: Celta, 1998.

BOURDIEU, Pierre. La noblesse de létat. Paris: Les Éditions de Minuit, 1989.

BRUM, Ceres K. "Vestida de prenda": sobre as significações da pedagogia tradicionalista das pilchas. Educação Santa Maria, v. 34, n. 1, p. 147-164, jan./abr. 2009.

GEERTZ, C. A interpretação das culturas. Rio de Janeiro: Guanabara, 1989.

HARTMANN, Luciana. Gesto, palavra e memória: performances narrativas de contadores de causos. Florianópolis: Ed. da UFSC, 2011. $310 \mathrm{p}$.

INGOLD, T. Da transmissão de representações à educação da atenção. Educação, Porto Alegre, v. 33, n. 1, p. 6-25, jan./abr 2010.

JESUS, Suzana Cavalheiro de. Pessoas na medida: processos de circulação de saberes sobre o Nande Reko Guarani na região das missões. Tese (Doutorado em Antropologia Social) - Centro de Filosofia e Ciências Humanas, Universidade Federal de Santa Catarina, Florianópolis, 2015.

LEVI-STRAUSS, Claude. A estrutura dos mitos. In: LEVI-STRAUSS, Claude. Antropologia Estrutural. Rio de Janeiro: Tempo Universitário, 1976.

NETO, G. Howes. De bota e bombacha: um estudo antropológico sobre as identidades gaúchas e o tradicionalismo. Dissertação (Mestrado em Ciências Sociais) - Centro de Ciências Sociais e Humanas, Universidade Federal de Santa Maria, 2009.

OLIVEN, Ruben. A parte e o todo: a diversidade cultural no Brasil-nação. Petrópolis: Vozes, 1990. 
ORTNER, Sherry B. Está a mulher para o homem, assim como a natureza para a cultura? In: ROSALDO, Michelle; LAMPHERE, Louise. A mulher, a cultura, a sociedade. Rio de Janeiro: Paz e Terra, 1979 [1974].

ORTNER, Sherry B. Narrativity in culture, history, and lives. Ann Harbor: University of Michigan, 1990.

ORTNER, Sherry. Anthropology and social theory: culture, power, and the acting subject. Durham: Duke University Press, 2006.

PINEAU, Gaston. As histórias de vida como artes formadoras da existência. In: SOUZA, Elizeu Clementino de; ABRAHÃO, Maria Helena Menna Barreto (org.). Tempos, narrativas e ficções: a invenção de si. Porto Alegre: EDPUCRS; Salvador: EDUNEB, 2006.

PRADO, Rosane Manhães. Um ideal de mulher: estudos dos romances de M. Delly. Perspectivas antropológicas da mulher, Rio de Janeiro: Zahar Editores, n. 2, p. 72-111, 1981.

RENAN, Ernest. Qu'est-ce qu'une nation? Paris: Kessinger, 1887.

REVISTA TEMPO. A mítica das mulheres heroínas: cultura gaúcha, mulher gaúcha. Revista Tempo, Rio Grande do Sul, n. 16, s/d.

RICOEUR, Paul. A memória, a história, o esquecimento. Trad. Alain François. Campinas: Unicamp, 2007.

ROCKWELL, E. La experiencia etnográfica: historia y cultura en los procesos educativos. Buenos Aires: Paidós, 2011.

SAHLINS, Marshall. Ilhas de história. Rio de Janeiro: Zahar, 2003.

SOUZA, C. P. et al. Memória e autobiografia: formação de mulheres e formação de professoras. Revista Brasileira de Educação, n. 2, p. 6176, maio/ago. 1996.

TILLY, Louise A. Gênero, história das mulheres e história social. Cadernos Pagu, n. 3, 1994. 